\title{
Influenza pandêmica A/H1N1: análise comparativa de alterações histopatológicas pulmonares
}

\author{
Pandemic influenza A/H1N1: comparative analysis of microscopic lung \\ histopathological findings
}

\author{
Roberta Marchiori ${ }^{1}$, Carla Sakuma de Oliveira Bredt ${ }^{2}$, Marcos Menezes Freitas de Campos ${ }^{1}$, \\ Fábio Negretti ${ }^{1}$, Péricles Almeida Delfino Duarte ${ }^{1}$
}

\begin{abstract}
RESUMO
Objetivo: Analisar as alterações histológicas pulmonares de quatro casos fatais de influenza pandêmica H1N1, correlacionando-os a características clínico-epidemiológicas. Métodos: Estudo retrospectivo e descritivo de dados de prontuários de quatro pacientes que faleceram por influenza H1N1 na Unidade de Terapia Intensiva de um hospital universitário, em 2009. Os pacientes haviam sido submetidos a aspirado de nasofaringe e as amostras foram analisadas pelo método de reação em cadeia da polimerase em tempo real. Biópsia pulmonar foi realizada no dia do óbito; um escore de intensidade das alterações histopatológica foi aplicado. Resultados: Três pacientes apresentaram reação em cadeia da polimerase em tempo real com resultado positivo (embora todos tivessem diagnóstico de influenza H1N1). As principais alterações histológicas identificadas foram: dano alveolar difuso exsudativo, com atelectasia de alvéolos; graus variáveis de hemorragia e edema alveolar; necrose e descamação do epitélio respiratório de vários bronquíolos; e formação de trombos. Uma das pacientes (gestante) apresentou, à histopatologia, achado de inclusão citomegálica. Conclusão: 0 s achados histopatológicos pulmonares em pacientes com influenza H1N1 fatal revelaram dano alveolar grave, com hemorragia alveolar e bronquiolite. Foi descrita uma coinfecção com citomegalovírus em paciente gestante.
\end{abstract}

Descritores: Vírus da influenza A subtipo H1N1; Pandemias; Unidades de terapia intensiva

\section{ABSTRACT}

Objective: To analyze the histopathological lung findings of four fatal cases of the $2009 \mathrm{H} 1 \mathrm{~N} 1$ influenza pandemic and their correlation with clinical and epidemiological characteristics. Methods: Descriptive data from medical records of four patients who died in the Intensive
Care Unit of a university hospital in 2009. Nasopharyngeal aspirate specimens were collected from the patients and were analyzed by real-time polymerase chain reaction. Lung biopsy was performed post mortem; a score of intensity for pathological changes was applied. Results: Three patients had positive real-time polymerase chain reaction (although all of them had a clinical diagnose of influenza H1N1). The main histopathological changes were: exudative diffuse alveolar damage with atelectasis; varying degrees of alveolar hemorrhage and edema, necrosis and sloughing of the respiratory epithelium in several bronchioli; and thrombus formation. One of the patients (the pregnant one) presented histopathological findings of cytomegalic inclusion. Conclusion: The pulmonary histopathological findings in patients with fatal 2009 H1N1 influenza pandemic disclosed intense alveolar damage and hemorrhage and severe bronchiolitis. A co-infection with cytomegalovirus was described in the pregnant patient.

Keywords: Influenza A virus, H1N1 subtype; Pandemics; Intensive care units

\section{INTRODUÇÃo}

As pandemias de gripe são imprevisíveis e associadas com alta morbidade e mortalidade, perturbações econômicas e sociais ${ }^{(1)}$. O vírus influenza tem alta capacidade de mutação; a variação antigênica, muitas vezes, torna o vírus irreconhecível ao sistema imunológico, e o novo subtipo se faz uma ameaça, podendo causar uma epidemia grave ou uma nova pandemia ${ }^{(2)}$.

Em 2009, uma nova cepa de influenza H1N1, com uma combinação de segmentos gênicos não previamente identificados em humanos ou animais, promoveu

\footnotetext{
Trabalho realizado no Hospital Universitário do Oeste do Paraná - HUOP, Cascavel (PR), Brasil.

${ }^{1}$ Hospital Universitário do Oeste do Paraná - HUOP, Cascavel (PR), Brasil.

2 Universidade Estadual do Oeste do Paraná - UNIOESTE, Cascavel (PR), Brasil.

Autor correspondente: Roberta Marchiori - Avenida Tancredo Neves, 3.224 - Santo Onofre - CEP 85806-470 - Cascavel (PR), Brasil - Tel.: (45) 3321-5151 - E-mail: betinhadoctor@hotmail.com

Data de submissão: 11/1/2012 - Data de aceite: 2/5/2012

Conflitos de interesse: não há.
} 
uma pandemia por influenza ${ }^{(3)}$. Inicialmente identificada no México e Estados Unidos, ela se alastrou mundialmente em poucas semanas, por meio de voos internacionais ${ }^{(4,5)}$.

O Brasil foi particularmente atingido: mais de 45 mil pessoas foram infectadas no ano epidemiológico de 2009, ocorrendo 2.051 óbitos. As regiões brasileiras Sul e Sudeste foram as mais intensamente afetadas ${ }^{(6,7)}$. No Paraná, em 2009, em 11 Unidades de Terapia Intensiva (UTI), em 6 cidades do Estado, no período de 45 dias, foram admitidos 63 pacientes com diagnóstico de H1N1, com alta mortalidade ${ }^{(8)}$. Em 2010, ainda ocorreram 1.623 casos de gripe A (H1N1), segundo dados da Secretaria de Saúde do Paraná(9).

\section{OBJETIVO}

Descrever quatro casos fatais de influenza pandêmica H1N1 de 2009; comparar e correlacionar com as características clínicas e epidemiológicas.

\section{MÉTODOS}

Estudo retrospectivo, sendo revisados os prontuários de quatro pacientes com diagnóstico clínico de infecção pelo vírus H1N1, internados na UTI do Hospital Universitário do Oeste do Paraná (HUOP), na cidade de Cascavel, em 2009, que foram a óbito e submetidos à biópsia pulmonar.

Coletaram-se os seguintes dados: gênero, idade, procedência, presença ou não de comorbidades, evolução clínica, dados laboratoriais e parâmetros ventilatórios.

Os quatro pacientes eram do gênero feminino. Uma paciente (paciente A) era portadora da síndrome da imunodeficiência adquirida (AIDS); um caso, (paciente B), apresentava história de retardo no desenvolvimento neuropsicomotor; havia uma gestante (paciente C) com 34 semanas de idade gestacional, previamente saudável; e uma paciente (paciente D) era portadora de insuficiência cardíaca, hepatopatia e insuficiência renal crônica. Todas as pacientes eram procedentes de cidades da região Oeste do Paraná, próxima à fronteira com Paraguai e Argentina.

As amostras de aspirado de nasofaringe foram analisadas no Laboratório Central do Estado em Curitiba (PR), pelo método de reação em cadeia da polimerase em tempo real (RT-PCR). As amostras foram processadas empregando-se o kit SuperScript III ${ }^{\mathrm{TM}}$ Platinum $^{\circledR}$ One-Step Quantitative RT-PCR System (Invitrogen, Carlsbad, EUA).

As pacientes estudadas foram submetidos à biópsia pulmonar post-mortem. O material foi fixado em forma- lina tamponada a $10 \%$. As amostras das biópsias foram submetidas à análise histológica, incluídas em blocos de parafina e, em seguida, coradas com hematoxilina-eosina, prata-metenamina de Grocott e Ziehl-Neelsen, para identificação de fungos e bacilos álcool-ácido resistentes (BAAR). Não foi realizada cultura das amostras.

Histologicamente, os casos foram avaliados por semiquantificação, atribuindo notas de 0 a 3 (0: ausente; 1: leve; 2: moderado; 3: intenso) para os seguintes parâmetros histológicos: tecido de granulação, membrana hialina, hemorragia alveolar; edema intra-alveolar, inflamação intersticial, efeito citopático, perivasculite, microtrombo, tromboembolismo, além de se procurarem evidências de bactérias, BAAR ou fungo (critério adaptado de Mauad et al.(10)). Após atribuídas as notas às cegas pelo patologista, realizou-se o somatório, obtendo-se um escore máximo de cada amostra. O presente trabalho foi aprovado pelo Comitê de Ética em Pesquisa da Universidade Estadual do Oeste do Paraná (UNIOESTE).

\section{RESULTADOS}

A média de idade das pacientes foi de 35,5 anos (21 a 65 anos).

A retirada cirúrgica do material foi realizada post-mortem em todas as pacientes. Os detalhes dos achados da microscopia das quatro pacientes são mostrados na tabela 1.

Os achados clínicos principais e sua incidência foram: febre e dispneia (presentes em 100\%), mialgia $(50 \%)$, tosse $(75 \%)$ e vômitos $(25 \%)$. Nenhum caso

Tabela 1. Achados histopatológicos pulmonares. Cada item é pontuado de 0 (ausente) a 3 (intenso)

\begin{tabular}{lcccc}
\hline \multirow{2}{*}{ Achado histopatológico } & \multicolumn{4}{c}{ Paciente } \\
\cline { 2 - 5 } & A & B & C & D \\
\hline Tecido de granulação & 1 & 2 & 3 & 2 \\
Membrana hialina & 3 & 3 & 1 & 2 \\
Hemorragia alveolar & 2 & 3 & 1 & 0 \\
Edema intra-alveolar & 1 & 3 & 1 & 2 \\
Inflamação intersticial & 3 & 2 & 3 & 3 \\
Efeito citopático & 0 & 0 & 0 & 0 \\
Perivasculite & 3 & 3 & 1 & 1 \\
Microtrombo & 3 & 3 & 2 & 0 \\
Tromboembolismo & 3 & 3 & 2 & 0 \\
Total & 19 & 23 & 14 & 10 \\
BAAR ou fungos & Negativo & Negativo & Negativo & Negativo \\
Inclusão citomegálica & - & - & Visualizada & - \\
\hline
\end{tabular}

BAAR: bacilos álcool-ácido resistentes. 
apresentou diarreia. Todos os casos necessitaram de ventilação mecânica. A insuficiência renal aguda se desenvolveu em dois casos, não sendo necessária diálise. As três pacientes que tiveram exame RT-PCR positivo apresentaram diagnóstico de síndrome da angústia respiratória aguda (SARA), que foi estabelecido pela presença de infiltrado pulmonar bilateral e pela relação pressão parcial arterial de oxigênio/fração de oxigênio no ar inspirado $\left(\mathrm{PaO}_{2} / \mathrm{FiO}_{2}\right) \leq 200$.

Uma das pacientes que apresentou hemoptise (paciente A) tinha plaquetopenia desde a admissão, enquanto outra (paciente C), que também teve essa complicação, era gestante e apresentava plaquetas normais.

Todos os casos receberam tratamento com oseltamivir por, no mínimo cinco dias, em dose conforme protocolo do Ministério da Saúde. Corticoterapia foi prescrita para todas as pacientes, bem como drogas vasoativas. A tabela 2 contém os dados clínico epidemiológicos das quatro pacientes.
Todas as pacientes apresentavam dano alveolar difuso em graus variáveis. Ocorreu hemorragia alveolar intensa em uma paciente, moderada em um caso e leve em outro. Observou-se pneumonite em graus variáveis, ocorrendo inflamação intersticial moderada em uma paciente e intensa em três. Em duas pacientes, foi observada perivasculite intensa e, em duas pacientes, de grau leve. A presença de microtrombos e tromboembolismo foi intensa em dois casos e moderada em um caso. Não foi evidenciado efeito citopático nos casos estudados e não houve evidência de infecção por BAAR ou fungo (Tabela 1).

A paciente $\mathrm{B}$ apresentou grau intenso de hemorragia e edema alveolar, sendo também a quem foi atribuído o maior escore e, clinicamente, teve a pior evolução respiratória.

A figura 1 mostra aspectos encontrados na histopatologia de uma das pacientes (paciente C). A histopatologia dessa paciente (que tinha RT-PCR positivo) foi

Tabela 2. Aspectos clínico-epidemiológicos e laboratoriais

\begin{tabular}{|c|c|c|c|c|}
\hline \multirow{2}{*}{ Características } & \multicolumn{4}{|c|}{ Pacientes } \\
\hline & A & B & C & D \\
\hline Idade & 35 anos & 21 anos & 21 anos & 65 anos \\
\hline \multicolumn{5}{|l|}{ Comorbidades } \\
\hline AIDS & $\operatorname{Sim}$ & Não & Não & Não \\
\hline Insuficiência cardíaca & Não & Não & Não & Sim \\
\hline Hepatopatia crônica (sem cirrose) & Não & Não & Não & $\operatorname{Sim}$ \\
\hline IRC não dialítica & Não & Não & Não & $\operatorname{Sim}$ \\
\hline Gestante & Não & Não & $\operatorname{Sim}$ & Não \\
\hline \multicolumn{5}{|l|}{ Exames laboratoriais à admissão } \\
\hline Leucócitos (células/mm³) & 2.570 & 7.170 & 5.640 & 15.700 \\
\hline Linfócitos (\%) & 12 & 4 & 22 & 5 \\
\hline $\mathrm{DHL}(\mathrm{U} / \mathrm{L})$ & 2.523 & 1.951 & 753 & 562 \\
\hline CPK (U/L) & 113 & 880 & 1.697 & 93 \\
\hline RT-PCR nasofaringe & Positivo & Positivo & Positivo & Negativo \\
\hline \multicolumn{5}{|l|}{ Evolução clínica } \\
\hline Insuficiência respiratória aguda + ventilação mecânica & $\operatorname{Sim}$ & Sim & $\operatorname{Sim}$ & $\operatorname{Sim}$ \\
\hline SARA & Sim & Sim & $\operatorname{Sim}$ & Não \\
\hline Pior $\mathrm{PaO}_{2} / \mathrm{FiO}_{2}$ & 91 & 71 & 61 & 221 \\
\hline Maior PEEP & 20 & 22 & 25 & 10 \\
\hline Insuficiência renal aguda & Sim & Sim & $\operatorname{Sim}$ & Não \\
\hline Uso de drogas vasoativas & Sim & Sim & Sim & Sim \\
\hline Tratamento com oseltamivir & $\operatorname{Sim}$ & Sim & $\operatorname{Sim}$ & $\operatorname{Sim}$ \\
\hline Tratamento com antibióticos & $\operatorname{Sim}$ & Sim & $\operatorname{Sim}$ & $\operatorname{Sim}$ \\
\hline Corticoterapia & $\operatorname{Sim}$ & Sim & $\operatorname{Sim}$ & $\operatorname{Sim}$ \\
\hline Tempo de início dos sintomas até o óbito (dias) & 15 & 16 & 17 & 10 \\
\hline Dias de internamento até o óbito & 8 & 10 & 10 & 10 \\
\hline
\end{tabular}




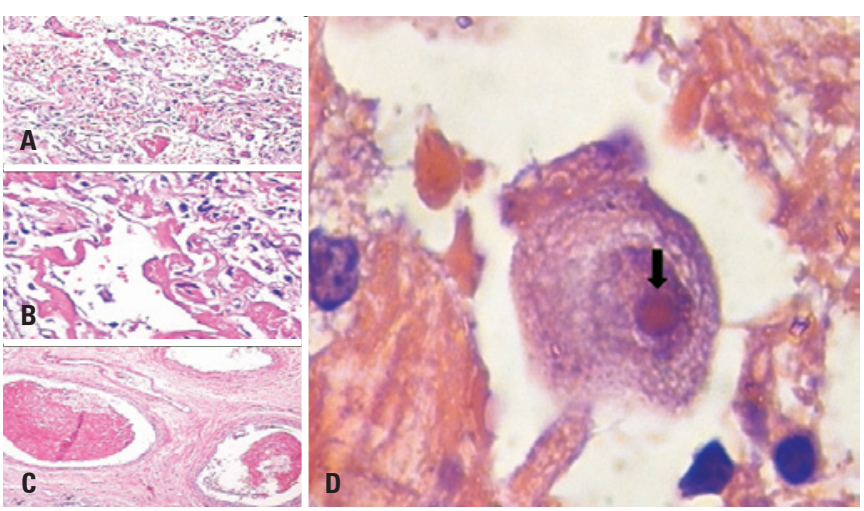

Figura 1. Achados histopatológicos pulmonares. (A) Pneumonite. (B) Espessamento de septos/membrana hialina. (C) Trombo/êmbolo vascular. (D) Inclusão citomegálica (seta)

compatível com associação com infecção por citomegalovírus, sendo visualizada inclusão citomegálica em epitélio bronquioloalveolar. As pacientes A e B apresentaram intensa perivasculite e tromboembolismo. Todos os casos apresentaram necrose e descamação do epitélio respiratório de vários bronquíolos, poucos alvéolos expandidos e o tecido pulmonar entre esses alvéolos era constituído por alvéolos atelectásicos.

\section{DISCUSSÃO}

Todos os casos relatados apresentaram insuficiência respiratória aguda grave relacionada à pandemia de 2009 pelo vírus A/H1N1 e necessitaram de intubação orotraqueal e internamento em UTI.

Os pacientes eram do gênero feminino, e os três casos confirmados laboratorialmente ocorreram em adultos jovens. Em um estudo com 21 pacientes brasileiros com influenza pandêmica 2009 confirmada, a mediana de idade encontrada foi de $34 \operatorname{anos}^{(10)}$. As comorbidades, provavelmente, estão relacionadas à maior gravidade e pior evolução dos casos. Em um estudo realizado nos Estados Unidos em 2009, com coleta de dados de prontuários de 272 pacientes com diagnóstico confirmado de H1N1, 73\% tinham pelo menos uma comorbidade ${ }^{(3,11)}$.

Entre as pacientes estudadas, nenhuma era obesa, diferente do observado em estudo de coorte realizado na Austrália e na Nova Zelândia, em UTIs, também em 2009. Dos 722 pacientes estudados, 601 tinham dados disponíveis sobre seu peso, sendo que $28,5 \%$ tinham índice de massa corporal $>35$, enquanto que, na Califórnia, dos 268 pacientes hospitalizados cuja massa corpórea era conhecida, $58 \%$ eram obesos ${ }^{(12)}$.

Todas as pacientes deste estudo apresentaram febre, dispneia e insuficiência respiratória aguda grave, necessitando de ventilação mecânica. A mialgia ocorreu em duas das pacientes e vômitos, em uma. Nenhu- ma paciente teve diarreia. Na epidemia do México, tosse, febre e dispneia foram os sinais clínicos predominantes ${ }^{(13)}$, enquanto que, em estudo nos Estados Unidos com 642 pacientes, a dispneia não foi relatada, em 94\% casos houve febre e, em $92 \%$, houve tosse. No entanto, nesse estudo, nem todos os pacientes avaliados foram hospitalizadas ${ }^{(14)}$. A evolução fatal, nos presentes casos estudados, pode ser explicada pelos fatores de risco para pior prognóstico presentes na amostra, como gestação e imunossupressão (paciente com AIDS).

Em relação às alterações laboratoriais (Tabela 2), a linfopenia foi detectada em todas as pacientes diagnosticadas como portadores da influenza pandêmica H1N1 de 2009, e plaquetopenia foi evidenciada na paciente do caso A, provavelmente relacionada ao diagnóstico de AIDS. Houve aumento significativo de desidrogenase láctica (DHL) nos três casos confirmados e de creatino fosfoquinase (CPK) em dois casos. No caso B, níveis acima de 1.000U/l de DHL foram detectados, sendo este o caso mais grave histologicamente e de pior evolução respiratória comparativamente, refletindo o maior grau de lesão pulmonar. No caso A, a paciente era portadora de AIDS, apresentava insuficiência respiratória grave e suspeita clínica de pneumocistose associada à infecção pelo vírus H1N1, o que poderia explicar o considerável aumento na dosagem de DHL. Elevação dos níveis de CPK que atingiu níveis acima de $1.000 \mathrm{U} / \mathrm{l}$ foi encontrada na gestante. Altos níveis de CPK, DHL e linfopenia também foram evidenciados em estudo retrospectivo no México em pacientes com insuficiência respiratória por influenza A H1N1 de 2009(13).

Em relação aos achados histopatológicos, os casos confirmados tiveram hemorragia alveolar em graus variáveis, dano alveolar difuso e edema alveolar, semelhante a pandemias prévias de influenza ${ }^{(15)}$. A paciente do caso B apresentou a pior evolução respiratória, tendo o maior escore de alterações histológicas analisadas, além de desenvolver SARA (aliás, o que ocorreu com todas as três pacientes confirmados do estudo). Ela também necessitou de posição prona em duas ocasiões, fato que pode estar associado à hemorragia e ao edema alveolar intensos observados na biópsia dessa paciente. Para a resolução da SARA, alguns mecanismos devem permanecer ativos, como a reabsorção do fluido do edema pulmonar a partir do espaço alveolar. Em pacientes com lesão pulmonar aguda, parece haver diminuição na capacidade da barreira epitelial alveolar de remover líquidos ${ }^{(16)}$. Estudos demonstram que a deficiência alveolar em transportar fluídos tem relação direta com a gravidade de apresentação clínica dos pacientes com SARA $^{(17,18)}$. Observou-se, em camundongos infectados 
pelo vírus influenza $\mathrm{A}$, que o vírus promove bloqueio do clearance de fluido alveolar, comprometendo diretamente as trocas gasosas ${ }^{(18)}$. A prevalência de infecção pelo vírus pandêmico H1N1 na gestação descrita na literatura está em torno de 7 a $9 \% \%^{(3,11)}$.

A paciente gestante (paciente $\mathrm{C}$ ) apresentava achados morfológicos compatíveis com citomegalovírus em epitélio bronquioloalveolar, infecção concomitante ao H1N1, o que pode ter contribuído à inflamação intersticial intensa detectada neste caso. É complicação incomum o relato de infecção por citomegalovírus causando pneumonite; porém esse vírus pode ser frequentemente isolado do lavado broncoalveolar de pacientes gravemente imunodeprimidos, não necessariamente causando pneumonia. O diagnóstico de pneumonia por citomegalovírus baseia-se na visualização direta de inclusão citomegálica e seu efeito citopático no tecido pulmonar ${ }^{(19)}$. Não foi encontrada, na literatura, descrição semelhante à deste caso de coinfecção entre vírus pandêmico H1N1 e citomegalovirose. Relata-se que a maioria das gestantes já foi previamente exposta à citomegalovirose; entretanto, cerca de $15 \%$ são suscetíveis a primo-infecção na gestação ${ }^{(20,21)}$. Houve, nesta paciente, evidência na lâmina de microtrombro e tromboembolismo moderado (segundo o escore supracitado), podendo estar relacionado ao estado de hipercoagulabilidade da gestação, mas, também, ao próprio vírus H1N1 de 2009, como relatado pelo Departamento de Patologia da Universidade de São Paulo (USP) ${ }^{(10,22)}$.

A paciente A, portadora de AIDS, apresentou intensa perivasculite e tromboembolismo, que pode estar relacionado ao derrame pleural extenso (por alteração da pressão hidrostática), necessitando de drenagem torácica fechada. Além disso, apresentou intensa inflamação intersticial, assim como a paciente do caso C, com suspeita de coinfecção por citomegalovírus. No entanto, no caso da paciente A, pode ter sido decorrente da suspeita clínica de pneumocistose concomitante, apesar da pesquisa de Pneumocystis jirovecii ter sido negativa na amostra de secreção traqueal analisada e do $P$. jirovecii não ter sido visualizado nas lâminas de biópsia disponíveis.

A paciente do caso $\mathrm{D}$ teve resultado de PCR negativo para H1N1 no aspirado de nasofaringe e orofaringe; entretanto, não foi realizada coleta do trato respiratório inferior, que poderia, segundo evidências da literatura, fornecer maior segurança no diagnóstico ${ }^{(23)}$. Até $10 \%$ dos casos de influenza H1N1 grave (admitidos em UTI) com RT-PCR positivo na secreção traqueal apresentaram exame negativo na secreção de oro/nasofaringe ${ }^{(24)}$. Apesar dessa consideração, a evolução clínica dessa paciente diferiu da dos outros casos. Ela apresen- tou leucocitose durante toda a internação; evoluiu com insuficiência respiratória aguda, porém só necessitou intubação orotraqueal no $3^{\circ}$ dia em UTI, além de não evoluir com SARA (as outras pacientes necessitaram ventilação mecânica imediatamente antes à admissão na UTI). Os pacientes de UTI com RT-PCR positivo apresentam pior desfecho clínico do que aqueles com resultado negativo ${ }^{(8)}$. Portanto, seria possível pressupor que o quadro de influenza H1N1, nesta paciente (mais idosa e com comorbidades crônicas), poderia não ter sido tão intenso, porém o desfecho foi desfavorável pela idade e pelas comorbidades. A alteração histológica pulmonar predominante da paciente $\mathrm{D}$ foi inflamação intersticial intensa, que é inespecífica, sendo que a hemorragia alveolar e a formação de trombos presentes, nas pacientes com exame positivo, estavam ausentes neste caso. A paciente do caso B teve o pior escore histológico, mas não apresentava nenhuma comorbidade identificada que pudesse justificar tal evolução; talvez possa ter ocorrido mutação no vírus infectante desta paciente, que o tornou mais virulento e capaz de promover as alterações histológicas observadas com maior intensidade.

Este artigo apresenta limitações, incluindo o fato de ser retrospectivo. Não foram realizadas culturas para bactérias das amostras respiratórias das pacientes, devido a problemas técnicos do laboratório. Também não foi realizada cultura das amostras das biópsias pulmonares, pois o material estava preparado com formol. O caso com provável associação de coinfecção por citomegalovírus não teve exames laboratoriais de confirmação, uma vez que não havia suspeita clínica quando do manejo da paciente.

\section{CONCLUSÃO}

Os quatro casos fatais de influenza pandêmica H1N1, com histopatologia pulmonar, revelaram como principais achados o dano alveolar difuso exsudativo, com atelectasia de alvéolos; graus variáveis de hemorragia e edema alveolar; necrose e descamação do epitélio dos bronquíolos; e formação de trombos. Também foi descrita uma rara coinfecção com citomegalovírus em uma das pacientes.

\section{REFERÊNCIAS}

1. World Health Organization. Avian influenza: assessing the pandemic threat [Internet]. 2005 [cited 2011 Jul 26]. Available from: http://whqlibdoc.who. int/hq/2005/WHO_CDS_2005.29.pdf

2. Salomon R, Webster RG. The influenza virus enigma. Cell. 2009;136(3):402-10.

3. Jain S, Kamimoto L, Bramley AM, Schmitz AM, Benoit SR, Louie J, Sugerman DE, Druckenmiller JK, Ritger KA, Chugh R, Jasuja S, Deutscher M, Chen S, 
Walker JD, Duchin JS, Lett S, Soliva S, Wells EV, Swerdlow D, Uyeki TM, Fiore AE, Olsen SJ, Fry AM, Bridges CB, Finelli L; 2009 Pandemic Influenza A (H1N1) Virus Hospitalizations Investigation Team. Hospitalized patients with 2009 H1N1 influenza in the United States, April-June 2009. N Engl J Med. 2009;361(20):1935-44.

4. Khan K, Arino J, Hu W, Raposo P, Sears J, Calderon F, et al. Spread of a novel influenza (H1N1) virus via global airline transportation. N Engl J Med. 2009;361(2):212-4.

5. Trifonov V, Khiabanian H, Rabadan R. Geographic dependence, surveillance, and origins of the 2009 influenza A (H1N1) virus. N Engl J Med. 2009;361 (2): 115-9.

6. Brasil. Ministério da Saúde. Secretaria de Vigilância em Saúde. Nota técnica $n^{0}$ 15/2010. Decreta o início da fase pós-pandêmica do vírus influenza pandêmica (H1N1) 2009 [Internet]. 2010 [citado 2012 Set 12]. Disponível em: http://portal.saude.gov.br/portal/arquivos/pdf/nt_15_fase_pos_pand virus_influ_a_10082010.pdf

7. Brasil. Ministério da Saúde. Secretaria de Vigilância em Saúde. Situação epidemiológica da Influenza Pandêmica (H1N1) 2009 no mundo e no Brasil, até a semana epidemiológica 47 de 2009. Informe Epidemiol. 2009 [citado 2012 Set 12];(11): [cerca de 11p]. Disponível em: http://portal.saude.gov.br/ portal/arquivos/pdf/boletim_influenza_se_47.pdf

8. Duarte PA, Venazzi A, Youssef NC, Oliveira MC, Tannous LA, Duarte CB, et al. Pacientes com infecção por vírus A (H1N1) admitidos em unidades de terapia intensiva do Estado do Paraná, Brasil. Rev Bras Ter Intensiva. 2009;21(3):231-6.

9. Paraná (Estado). Secretaria do Estado de Saúde. Situação epidemiológica no Paraná conforme dados oficiais da Secretaria de Estado da Saúde no ano de 2010. Bol Epidemiol [Internet]. 2010 [citado 2012 Ago 12];(12):[cerca de 3 p.]. Disponível em: http://www.gripea.pr.gov.br/arquivos/File/BOLETIM/ BoletimEpidemiologi12-2010.pdf

10. Mauad T, Hajjar LA, Callegari GD, Silva LF, Schout D, Galas FR, et al. Lung pathology in fatal novel human influenza A (H1N1) infection. Am J Respir Crit Care Med. 2010;181(1):72-9.

11. ANZIC Influenza Investigators, Webb SA, Pettilä V, Seppelt I, Bellomo R, Bailey M, et al. Critical care services and 2009 H1N1 influenza in Australia and New Zealand. N Engl J Med. 2009;361(20):1925-34.

12. Louie JK, Acosta M, Winter K, Jean C, Gavali S, Schechter R, et al. Factors associated with death or hospitalization due to pandemic 2009 influenza A(H1N1) infection in California. JAMA. 2009; 302(17):1896-902.

13. Perez-Padilla R, de la Rosa-Zamboni D, Ponce de Leon S, Hernandez M, Quiñones-Falconi F, Bautista E, Ramirez-Venegas A, Rojas-Serrano J, Ormsby
CE, Corrales A, Higuera A, Mondragon E, Cordova-Villalobos JA; INER Working Group on Influenza. Pneumonia and respiratory failure from swineorigin influenza A (H1N1) in Mexico. N Engl J Med. 2009;361 (7):680-9.

14. Novel Swine-Origin Influenza A (H1N1) Virus Investigation Team, Dawood FS, Jain S, Finelli L, Shaw WM, Lindstrom S, et al. Emergence of a novel swine-origin influenza A (H1N1) virus in human. N Engl J Med. 2009;360(25): 2605-15.

15. Taubenberger JK, Morens DM. The pathology of influenza virus infections. Annu Rev Pathol. 2008;3:499-522.

16. Matthay MA. Alveolar fluid clearance in patients with ARDS: does it make a difference? Chest. 2002;122(6 Suppl):340S-343S.

17. Sartori $C$, Matthay MA. Alveolar epithelial fluid transport in acute lung injury: new insights. Eur Respir J. 2002;20(5):1299-313.

18. Wolk KE, Lazarowski ER, Traylor ZP, Yu EN, Jewell NA, Durbin RK, et al. Influenza A virus inhibits alveolar fluid clearance in BALB/c mice. Am J Respir Crit Care Med. 2008;178(9):969-76.

19. Huang L, Crothers K. HIV-associated opportunistic pneumonias. Respirology. 2009;14(4):474-85.

20. Figueiró-Filho EA, Senefonte FR, Lopes AH, Morais 00, Souza Junior VG, Maia TL, et al. Freqüência das infecções pelo HIV-1, rubéola, sífilis, toxoplasmose, citomegalovírus, herpes simples, hepatite $B$, hepatite $C$, doença de Chagas e HTLV I/II em gestantes, do Estado de Mato Grosso do Sul. Rev SocBras Med Trop. 2007;40(2):181-7.

21. Serra FC, Machado J, Nicola MH, Jorge MC, Cruz LE, Giordano MV, et al. Soroprevalência de citomegalvírus em gestantes brasileiras de classe socioeconômica favorecida. DST J Bras Doenças Sex Transm. 2009;21(1): 12-5.

22. Shieh WJ, Blau DM, Denison AM, Deleon-Carnes M, Adem P, Bhatnagar J, et al. 2009 pandemic influenza A (H1N1): pathology and pathogenesis of 100 fatal cases in the United States. Am J Pathol. 2010;177(1):166-75.

23. World Health Organization. Clinical management of human infection with pandemic (H1N1) 2009: revised guidance [Internet] [cited 2012 Set 12] Available from: http://www.who.int/csr/resources/publications/swineflu/ clinical_management_h1n1.pdf

24. Rello J, Rodríguez A, Ibañez P, Socias L, Cebrian J, Marques A, Guerrero J, Ruiz-Santana S, Marquez E, Del Nogal-Saez F, Alvarez-Lerma F, Martínez S, Ferrer M, Avellanas M, Granada R, Maraví-Poma E, Albert P, Sierra R, Vidaur L, Ortiz P, Prieto del Portillo I, Galván B, León-Gil C; H1N1 SEMICYUC Working Group. Intensive care adult patients with severe respiratory failure caused by Influenza A ( H1N1)v in Spain. Crit Care. 2009;13(5):R148. 